\title{
The impact of L-carnitine on nutritional status in juvenile idiopathic dilated cardiomyopathy
}

\author{
Estela Azeka*
}

\begin{abstract}
Cardiomyopathies are defined as diseases of the myocardium associated with ventricular dysfunction. They can be classified as: dilated, hypertrophic, restrictive or arrhythmogenic right ventricular. There are also nonclassified types: fibroelastosis, noncompacted myocardium, systolic dysfunction with minimal dilation, mitochondrial disease. ${ }^{1}$
\end{abstract}

Dilated cardiomyopathies are characterized by ventricular dilation and systolic dysfunction. They can be idiopathic, familial/genetic due to innate errors of metabolism, caused by muscular dystrophy, viral and/or autoimmune infections, drugs, toxins, Kawasaki disease and nonspecific histology. Pathological findings include increase in the size and weight of the heart, ventricular dilation, a normal thickness wall and greater cardiac dysfunction than with fibrosis. Concerning the incidence of cardiomyopathy in infants and children, the Pediatric Cardiomyopathy Registry held in the United States relates annual incidence of cardiomyopathy in children from zero to 18 years of 0.6 per 100,000 people. Lipshultz et al. ${ }^{2}$ relate that among infant patients, males predominate and that the most common type of cardiomyopathy was dilated. The significance of cardiomyopathies lies in the fact that the disease is severe among children who present symptoms, since $40 \%$ of these can progress to refractory heart failure and require transplantation or die within the first 2 years. Neither time for transplantation nor fatal outcomes have

* PhD. Councelor of the International Pediatric Transplantation Association (IPTA). Assistant physician, InCor, Hospital das Clínicas, Medicine School, Universidade de São Paulo (FMUSP), São Paulo, SP, Brazil.

Suggested citation: Azeka E. The impact of L-carnitine on nutritional status in juvenile idiopathic dilated cardiomyopathy. J Pediatr (Rio J). 2005;81:355-6. improved over the last 35 years, either in developed countries or those in development.

Dilated cardiomyopathy can manifest with congestive heart failure (CHF), arrhythmia and sudden death.

The most common symptoms of heart failure in infants include tachypnea, tachycardia and dyspnea when nursing. 3,4 Other signs are hepatomegaly, a galloping rhythm on physical examination, and cardiomegaly, pulmonary edema on chest x-ray. Older children may exhibit tachycardia and tachypnea, but the typical manifestation is fatigue and intolerance of exercise; with lack of appetite and problems with pondero-statural growth being common. Also observed are venous distension and peripheral edema. Adolescents present similar symptoms to adults, including dyspnea, tachypnea, fatigue, intolerance of exercise, orthopnea, paroxysmal nocturnal dyspnea and gastrointestinal symptoms. The modified classification developed by the New York Heart Association (NYHA) ${ }^{5}$ is useful for quantifying heart failure in children, as is the Ross ${ }^{6}$ scale for evaluating heart failure in infants.

Management of symptoms with digitalis and diuretics and angiotensin-converting enzyme (ACE) inhibitors is the basic therapy for the majority of patients. However, $\mathrm{CHF}$ can progress in some patients, either immediately or in the long term, developing to the point when heart transplantation is indicated.

Studies in adults have demonstrated that beta-blockers have a beneficial effect, improving ejection fraction, reducing mortality and need for hospitalizations and improving NYHA functional class and tolerance of exercise. In children, the use of beta-blockers has been shown to improve ventricular function, but there is just one doubleblind and randomized study in the literature ${ }^{7}$ that enrolled children, awaiting heart transplantation, who had dilated cardiomyopathy and severe CHF. 
Treatment strategies for chronic CHF in children have traditionally followed the treatment recommendations for treatment of CHF in adults patients. Specific pharmacological treatment for children suffering from cardiomyopathy is rare, like for example, muscular diseases like Duchenne dystrophy and mitochondrial disease. The majority of genetic diseases do not have a specific etiologic treatment.

Nevertheless, the fact that the etiology and pathophysiology of CHF in children exhibits certain distinct characteristics justifies the elaboration of randomized, prospective studies to improve the medication-based treatment of $\mathrm{CHF}$ in this age group. Such data will provide information that will be of use for appropriate management, optimizing the pharmacological treatment of $\mathrm{CHF}$ in children. Heart transplantation has been used as a treatment option for children with severe $\mathrm{CHF}^{8}$ but it is limited by the scarcity of potential donors. Therapeutic strategies that could reduce the waiting lists or even delay the need for heart transplantation remain the primary objective for this group of patients.

In this context, the studies undertaken by Azevedo et al. assume fundamental importance. ${ }^{9,10}$ Recently, the authors demonstrated that malnutrition ${ }^{9}$ is an independent marker of death among children and adolescents suffering from dilated cardiomyopathy. Following the same line of research, the authors studied the beneficial effects of the use of carnitine in children with dilated cardiomyopathy. In this prospective, open-label study of 11 children, compared with 40 controls, paired for age and sex, oral L-carnitine oral (100 $\mathrm{mg} / \mathrm{kg} /$ day) was administered in addition to the standard treatment. The L-carnitine group was weighed 118 times and the controls 264, in addition to 65 echocardiograms of the L-carnitine group and 144 of the controls. They concluded that the introduction of L-carnitine at the start of treatment for juvenile dilated cardiomyopathy, with the exception of those innate errors of metabolism for which Lcarnitine is not beneficial, has the potential to accelerate the recovery of nutritional status and help prevent or revert cachexia, which all patients with heart failure can develop. The authors also observed improved ventricular function. ${ }^{10}$

\section{References}

1. Richardson P, McKenna W, Bristow M, Maisch B, Mautner B, O'Connell J, et al. Report of the 1995 World Health Organization/ International Society and Federation of Cardiology Task Force on the Definition and classification of cardiomyopathies. Circulation. 1996;93:841-2.

2. Lipshultz SE, Sleeper LA, Towbin JA, Lowe AM, Orav EJ, Cox GF, et al. The incidence of pediatric cardiomyopathy in two regions of the United States. N Engl J Med. 2003;348:1647-55.

3. Kay JD, Colan SD, Graham TP, Durbam NC. Congestive heart failure in pediatric patients. Am Heart J. 2001;142:923-8.

4. Auslender M. Pathophysiology of pediatric heart failure. Progress Pediatr Cardiol. 2000;11:175-84.

5. Connolly D, Rutkowski M, Auslender M, Artman M. The New York University Pediatric Heart Failure Index: a new method of quantifying chronic heart failure severity in children. J Pediatr. 2001; 138:644-8.

6. Ross RD, Bollinger RO, Pinsky WW. Grading the severity of congestive heart failure in infants. Pediatr Cardiol. 1992;13:72-5.

7. Azeka E, Ramires JA, Valler C, Bocchi E. Delisting of infants and children from the heart transplantation waiting list after carvedilol treatment. J Am Coll Cardiol. 2002;40:2034-8.

8. Azeka E, Marcial MB, Jatene M, Auler Jr JO, Ramirez JA. Eightyear experience of pediatric heart transplantation: clinical outcome using non-invasive methods for the evaluation of acute rejection. Pediatr Transplant. 2002;6:208-13.

9. Azevedo VM, Albanesi Filho FM, Castier MB, Santos MA, Tura BR. O impacto da desnutrição na cardiomiopatia dilatada idiopática na infância. J Pediatr (Rio J). 2004;80:211-6.

10. Azevedo VM, Albanesi Filho FM, Santos MA, Castier MB, Cunha MO. O papel da L-carnitina no estado nutricional e na evolução ecocardiográfica da cardiomiopatia dilatada idiopática da infância. J Pediatr (Rio J). 2005;81:368-72. 